\title{
The Effectiveness of Heated Humidified High-flow Nasal Cannula in Children with Severe Bacterial Pneumonia in the Emergency Department
}

\author{
(D) Ali Yurtseven'1, (1) Eylem Ulaş Saz \\ 'Ege University Faculty of Medicine, Department of Pediatrics, İzmir, Turkey
}

\begin{abstract}
Aim: The provision of appropriate respiratory support has a great role in outcome of patients presenting to the emergency department (ED) with respiratory distress (RD) associated with severe pneumonia. In recent years, heated humidified high-flow nasal cannula (HHHFNC) therapy has become one of the most popular non-invasive respiratory support modalities in all pediatric settings. In this study, we aimed to assess whether the use of HHHFNC therapy is associated with reduced RD and improvements in hypoxemia among children with severe bacterial pneumonia (SBP) presenting to the ED.
\end{abstract}

Materials and Methods: We performed a prospective observational study of patients with SBP admitted to a tertiary children's hospital pediatric ED who received HHHFNC therapy within the 2 year study period. The primary outcome was accepted as treatment failure (It was defined as a clinical escalation in respiratory status) and an increase in peripheral capillary oxygen saturation $\left(\mathrm{SpO}_{2}\right)$. Secondary outcomes covered a decrease of respiratory rate (RR), heart rate (HR), and rates of weaning, intubation and intensive care unit (ICU) admission.

Results: Fifty-six patients were included in this analyses. Treatment failure was $21.5 \%(12 / 56)$. Among these patients, 9 (16\%) were intubated and $3(5.5 \%)$ placed on bilevel positive airway pressure. The mean initial RR values were significantly higher in the non responders group than the responder group $(p=0.027)$. Significant variation in the intubation rate or the ICU admission rate was not determined. At the $2^{\text {nd }}$ hour, the fall in $\mathrm{RR}(p<0.001), \mathrm{HR}(p<0.001)$, and the increase of $\mathrm{SpO}_{2}(p<0.001)$ were significantly evident when compared with the beginning.

Conclusion: HHHFNC therapy reached treatment success in a majority of the patients with SBP and provided an early effect. Patients with higher RRs responded less to HHHFNC. Further larger studies are needed to assess the impact of HHHFNC compared with other possible therapies.

Keywords: Pediatric emergency department, hypoxia, oxygenation, pneumonia, high-flow nasal cannula

\section{Introduction}

Severe bacterial pneumonia (SBP) is a common lifethreatening disease for the pediatric population, and is more common in infants and young children (1). Respiratory distress (RD) due to SBP, which is one of the most common reasons for emergency department (ED) presentations, causes millions of hospital admissions and hundreds of thousands of deaths every year worldwide (1-3). In the 1980s, the World Health Organization (WHO) developed a case management strategy aiming to reduce deaths from pneumonia (4). While it suggests that in severe pneumonia cases, the cornerstones of management are antibiotic and supportive therapy, the most important basis for the 
management strategy was hypoxemia which is common and potentially associated with increased risk of death (4-7). Early detection of hypoxemia, and administration of oxygen therapy also improves the outcome of children with SBP (7). The most effective way to treat hypoxemia is oxygen supplementation (6). There have been various oxygen treatment options for a long time but these may be insufficient. Heated humidified high-flow nasal cannula (HHHFNC) therapy has recently started to become an alternative oxygen giving method for the treatment of acute RD due to pneumonia (7).

HHHFNC can be set up quickly and is a reliable noninvasive respiratory support therapy method (8). Even though HHHFNC delivers high flow oxygen, owing to humidification and heating it doesn't damage the respiratory mucosa (9). HHHFNC also creates a positive-end expiratory pressure $(8,9)$.

HHHFNC oxygen treatment, which has been reported to be more effective than standard oxygen, decreases the rate of intubation/invasive ventilation in severe pneumonia (1012). Although it probably has some helpful effects, there is limited evidence on using this treatment option in patients with pneumonia $(8,9)$.

There are already a few studies which evaluate the treatment success of HHHFNC for children with SBP with almost all of them being conducted in the intensive care unit (ICU) $(13,14)$. The goal of this prospective clinical study was to determine whether the use of HHHFNC therapy is associated with a reduction in severity among children with SBP presenting to the ED.

\section{Materials and Methods}

This study was done as a prospective observational study in a pediatric ED. The study period was between May 2017 and April 2019. The ED is a tertiary-care teaching center and approximately 80,000 patients are admitted annually. The local Institutional Review Boards approved the study, and we obtained written informed consent for each patient. We maintained patient confidentiality during all processes of the study.

The diagnosis and the severity of pneumonia were made based on the Pediatric Infectious Diseases Society clinical practice guideline (15). All patients who were included in the study had fever or fever history, tachypnea, alveolar infiltration or consolidation on chest $\mathrm{X}$-ray and high serum biomarkers values (procalcitonin level $>0.25 \mathrm{ng} / \mathrm{mL}$ and/or C-reactive protein level $>40 \mathrm{mg} / \mathrm{L}$ and/or absolute neutrophil count $>10,000 / \mathrm{mm}^{3}$ ) supporting bacterial infection (16-18).
Patients who were diagnosed with bacterial pneumonia, aged between 0-18 years and having at least one of clinical features of severe pneumonia [1- Moderate to severe RD (RR $>70$ breaths/minute for infants, RR > 50 breaths/minute for older children, moderate/severe suprasternal, intercostal, or subcostal retractions (<12 months), severe difficulty breathing ( $\geq 12$ months), grunting, nasal flaring, apnea, significant shortness of breath) 2- Cyanosis 3- Altered mental status 4- Hypoxemia (sustained oxygen saturation $<90$ percent in room air at sea level) 5- Not feeding (infants) or signs of dehydration (older children) 6- Capillary refill $\geq 2$ seconds) with temperature $\geq 38.5^{\circ} \mathrm{C}$ and tachycardia were included in this study.] Patients who were intubated and/or admitted to the ICU on arrival at the ED; patients who had $\mathrm{PCO}_{2}$ (venous) greater than 55 prior to HHHFNC initiation; patients who presented with severe septic shock; and patients who were complicated with pneumothorax or nasal trauma were excluded.

Pediatric emergency medicine specialists examined the patients for acute life-threatening conditions caused by pneumonia after the triage assessment. Following this stage, a nurse monitored vital signs $\left[\mathrm{SpO}_{2}\right.$, blood pressure, $R R$, heart rate $(H R)]$, achieved vascular access, and obtained venous blood gas. After obtaining parental consent and confirmation of eligibility for study inclusion, HHHFNC therapy was initiated. Initially, a flow rate of $10 \mathrm{~kg} 2-\mathrm{L} / \mathrm{kg} /$ min and thereafter a flow rate of $0.5 \mathrm{~L} / \mathrm{kg} / \mathrm{min}$ for every kilogram was delivered via nasal cannula. The total flow range was arranged as 6-50 L/min. $\mathrm{FiO}_{2}$ was adjusted to a minimum value to ensure $\mathrm{SpO}_{2}$ within a range of $94-99 \%$ and the humidifier was auto-set at $37^{\circ} \mathrm{C}$. Optiflow of Fisher \& Paykel Healthcare Auckland, New Zealand which is a heated and humidified HHHFNC delivery system was used. The optiflow junior nasal cannula (neonatal, infant and pediatric size) and the optiflow nasal cannula (adult size) which provides up to $50 \mathrm{~L} / \mathrm{min}$ flow rate were utilized on all participants. All children also received standard management for bacterial pneumonia, including parental antibiotics and supportive care treatment. In addition, if necessary, patients were given therapy for comorbidities.

After HHHFNC initiation, the nurse and ED physician recorded hourly the clinical parameters ( $\mathrm{RR}, \mathrm{HR}$ and $\mathrm{SpO}_{2}$ ). Achievement of all of the following criteria was accepted as weaning criteria. The criteria were: decreased RR (for infants $\leq 2$ months $<60$ bpm, 2-12 months $<50$ bpm, 1-5 years $<40 \mathrm{bpm}$ and $>5$ years $<20 \mathrm{bpm}$ ); absence of dyspnea including accessory muscle use, retractions, nasal flaring, and grunting; $\mathrm{SpO}_{2}$ reached $\geq 90 \%$ with $\mathrm{FiO}_{2}<30 \%$; no confusion. If severe RD and/or $\mathrm{SpO}_{2}<90 \%$ with $\mathrm{FiO}_{2}>50 \%$ 
continued, ICU admission was required. HHHFNC therapy was continued in patients who had HHFNC failure or insufficient response, until their transfer to the ICU. If needed, intubation was performed at any stage of observation. The protocol continued for at least 24 hours and all stages of treatment [requirement of another modality of noninvasive ventilation (NIV), invasive ventilation, weaning, restart of HHHFNC therapy] were observed.

If one or more of the following criteria within 24 hours of initiation HHHFNC therapy were observed, it was considered as treatment failure. These criteria were; $\mathrm{SpO}_{2}$ $<90 \%$ continued even if $\mathrm{FiO}_{2}>50 \%$; persistent tachypnea (patients aged 0-12 months with RR $>70$ bpm and for $>12$ months $>50 \mathrm{bpm}$ ); development of hypoventilation; $\mathrm{PCO}_{2}$ sustained over $50 \mathrm{mmHg}$. Patients who had treatment failure received bilevel positive airway pressure (BiPAP) or intubation. The primary outcome was defined as treatment failure within 24 hours after HHHFNC initiation and recovery in $\mathrm{SpO}_{2}$ (after two hours of the treatment). It was reported that the highest risk of failure is within the first 24 hours of the therapy and the expected potential benefits of HHHFNC therapy are improvement in RR and HR, achievement of weaning and the avoidance of intubation or ICU admission $(9,19)$. Additionally, secondary outcomes were reduction of $\mathrm{RR}$ and $\mathrm{HR}$, a rise of $\mathrm{SpO}_{2}$ and the rate of weaning after two hours of the treatment; rates of intubation and ICU admission within the first 24 hours.

The investigators trained the ED nurses and physicians about HHHFNC therapy before starting the study. This study was approved by Ethics Board of Ege University (approval number: 17-4/6).

\section{Statistical Analysis}

SPSS for Windows (ver. 22.0 SPSS Inc., IL, USA) was used for all analyses. Wilcoxon's test was performed to compare the changes in $\mathrm{SpO}_{2}, \mathrm{RR}, \mathrm{HR}$, and the rate of weaning. Student's t-test, chi-squared and Mann-Whitney $U$ test were used to analyze the differences of the baseline characteristics of responder and non-responder groups (age, sex, admitted season, comorbidity, the initial values of $\mathrm{SpO} 2, \mathrm{RR}, \mathrm{HR}, \mathrm{PCO}_{2}, \mathrm{PO}_{2}$, and $\mathrm{pH}$ ) as appropriate. A twotailed probability value $(p)$ of less than 0.05 was accepted as significant.

\section{Results}

During the study period, 92 patients presented to the ED with a diagnosis of SBP and 56 of them (61\%) were assessed as eligible for the final analysis (Figure 1). The mean age was $45.3 \pm 41.2(2-168)$ months, and 55.4\% ( $n=31)$ were male. In the study group, 30 (53\%) patients had chronic illnesses; 11 (20\%) neuromuscular diseases, 8 (14\%) chronic lung diseases, $5(9 \%)$ chronic cardiac disease, 4 (7\%) immunodeficiency, 1 (2\%) malignancy and 1 (2\%) malnutrition. The mean initial RR values of the non-responder group were significantly higher than the responder group $(p=0.027)$. The other baseline characteristics of the responder group were similar to non-responder group (Table 1).

Among the 12 (21.4\%) patients with treatment failure, 9 $(16 \%)$ were intubated. BiPAP was successfully used to treat the remaining 3 patients. A total of 12 (21.5\%) patients were admitted to the ICU. There was no statistical difference between patients who had chronic illnesses and others in terms of intubation rate, ICU admission rate and treatment failure.

At the second hour of the therapy, 21 (37.5\%) patients received the weaning protocol, $\mathrm{HHHFNC}$ therapy continued in 23 patients (41\%). The reductions in $R R(p<0.001)$, and in $\mathrm{HR}(p<0.001)$, and the increase in $\mathrm{SpO}_{2}(p<0.001)$ were significantly higher at the second hour of evaluation when compared with the baseline (Table 2).

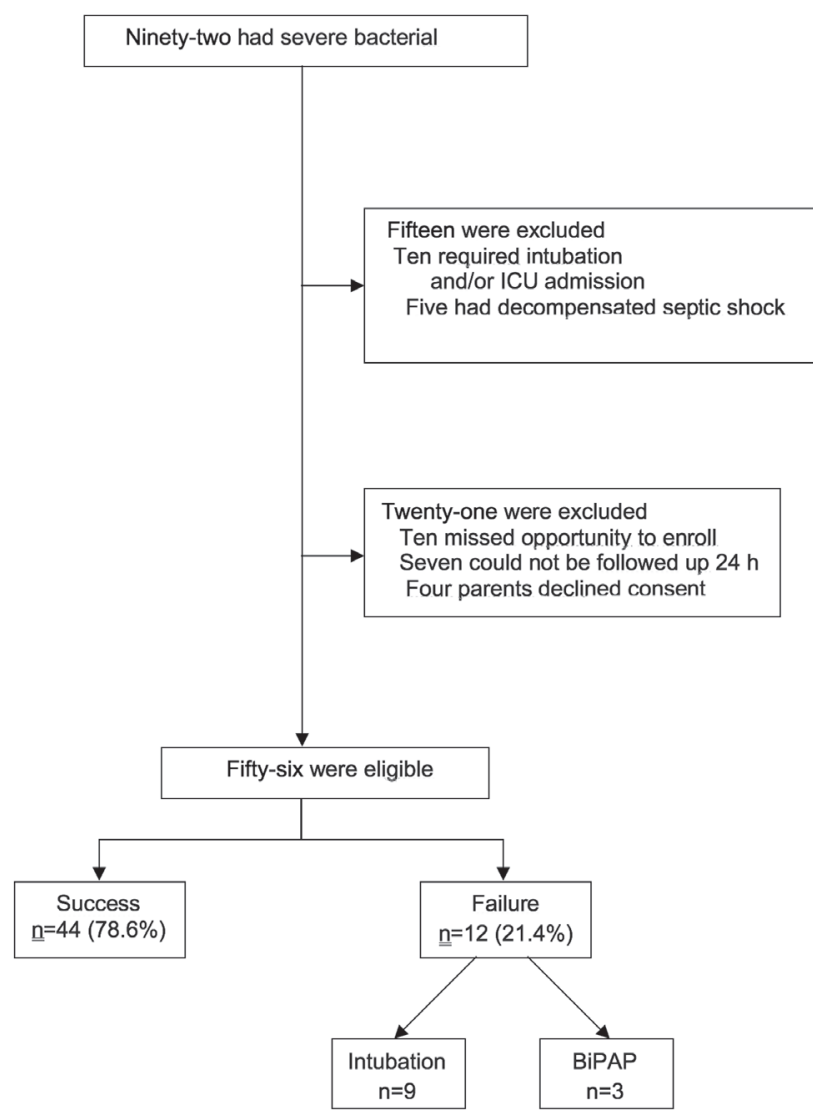

Figure 1. Flowchart of the study population and the primary outcomes 
Table I. Comparison of patient characteristics at admission between responder and non-responder groups

\begin{tabular}{|c|c|c|c|c|}
\hline & $\begin{array}{l}\text { Responder group } \\
\text { (HFNC therapy success) }(n=44)\end{array}$ & $\begin{array}{l}\text { Non-responder group } \\
\text { (HFNC therapy failure) }(n=12)\end{array}$ & Total $(n=56)$ & p \\
\hline \multicolumn{5}{|l|}{ Sex } \\
\hline Male (\%) & $24(54.5)$ & $7(58.3)$ & $31(55.3)$ & 0.540 \\
\hline Mean age (months) ( \pm SD) & $45.7(20)$ & $43.7(26)$ & $45.3(21)$ & 0.878 \\
\hline Prematurity (<37 weeks) & $9(20.4)$ & $3(25)$ & $12(21.4)$ & 0.707 \\
\hline Chronic illnesses & $23(52)$ & $7(58)$ & $30(53)$ & 0.755 \\
\hline \multicolumn{5}{|l|}{ Admitted season } \\
\hline Winter & $22(50)$ & $4(33)$ & $26(46)$ & \multirow{4}{*}{0.451} \\
\hline Spring & $9(20)$ & $4(33)$ & $13(23)$ & \\
\hline Autumn & $7(16)$ & $1(9)$ & $8(14)$ & \\
\hline Summer & $6(14)$ & $3(35)$ & $9(16)$ & \\
\hline Initial respiratory rate (breath/min) & $\begin{array}{l}59.7(10.4) \\
(40-80)\end{array}$ & $\begin{array}{l}67.2(9.1) \\
(46-82)\end{array}$ & $\begin{array}{l}61.3(10.5) \\
(40-82)\end{array}$ & 0.027 \\
\hline Initial heart rate (beat/min) & $\begin{array}{l}157.8(21.9) \\
(106-208)\end{array}$ & $\begin{array}{l}157.1(18.1) \\
(135-211)\end{array}$ & $\begin{array}{l}157.6(21.1) \\
(106-211)\end{array}$ & 0.918 \\
\hline Initial $\mathrm{SpO}_{2} \sharp(\%)$ & $\begin{array}{l}91.3(3.8) \\
(75-100)\end{array}$ & $\begin{array}{l}91(3.6) \\
(72-100)\end{array}$ & $\begin{array}{l}91.2(3.8) \\
(72-100)\end{array}$ & 0.836 \\
\hline Initial venous $\mathrm{PCO}_{2}+(\mathrm{mmHg})$ & $\begin{array}{l}42.3(7.5) \\
(29-54)\end{array}$ & $\begin{array}{l}43.2(6.3) \\
(33-54)\end{array}$ & $\begin{array}{l}42.5(7.5) \\
(29-54)\end{array}$ & 0.707 \\
\hline Initial venous $\mathrm{PO}_{2} \dagger(\mathrm{mmHg})$ & $\begin{array}{l}59.5(14.4) \\
(25-85)\end{array}$ & $\begin{array}{l}56.7(17.5) \\
(33-87)\end{array}$ & $\begin{array}{l}57.5(15.5) \\
(25-87)\end{array}$ & 0.622 \\
\hline Initial venous $\mathrm{pH}$ & \begin{tabular}{|l}
$7.35(0.1)$ \\
$(7.21-7.52)$
\end{tabular} & $\begin{array}{l}7.36(0.1) \\
(7.22-7.50)\end{array}$ & $\begin{array}{l}7.35(0.1) \\
(7.21-7.51)\end{array}$ & 0.525 \\
\hline
\end{tabular}

Table II. Secondary outcomes in the study cohort

\begin{tabular}{|c|c|c|c|c|}
\hline & Initial values & $\begin{array}{l}\text { At the } 2^{\text {nd }} \text { hour of HFNC } \\
\text { therapy }\end{array}$ & $\mathbf{p}$ & Mean difference \\
\hline Reduction in RR $\ddagger$ & $61.3(10.5)$ & $50.6(11.8)$ & $<0.001$ & $-10.7(-7.9,-13.5)$ \\
\hline Reduction in $\mathrm{HR}^{\dagger}$ & $157.6(21.1)$ & $141.4(24.2)$ & $<0.001$ & $-16.2(-11,-21.4)$ \\
\hline Rise in $\mathrm{SpO}_{2}{ }^{*}$ & $91.2(3.8)$ & $96.4(4.3)$ & $<0.001$ & $5.2(2.2-8.2)$ \\
\hline
\end{tabular}

No patient died and therapy-related side effects such as pressure injuries or pneumothorax had not developed within 24 hours.

\section{Discussion}

In this prospective observational study, we investigated the effectiveness of HHHFNC therapy and affecting factors in children with RD due to SBP in a tertiary care academic pediatric ED. The results of our study have shown that HHHFNC is a safe and effective form of noninvasive respiratory support method for patients with SBP. HHHFNC therapy was significantly efficient for $\mathrm{RR}, \mathrm{HR}$ and $\mathrm{SpO}_{2}$ at the second hour of the therapy, while treatment success was achieved in $78.5 \%$ of patients. Therapy failure was more common in patients with a higher respiratory rate.

Although appropriate antibiotics and supportive care treatment are indispensable for children with pneumonia, it is stated that hypoxemia is one of the most important risk factors for mortality and morbidity in these patients $(6,20)$. As shown in meta-analysis, hypoxemia, which is defined with a cut-off for $\mathrm{SpO}_{2}$, below $90 \%$, is associated 
with significantly increased odds of death from acute lower respiratory infections (odds ratio: 5.47, 95\%, confidence interval: 3.93 to 7.63 ) in children (21). Previously published data indicates that delays in diagnosis or management of hypoxemia due to pneumonia may be the main cause of these high rates in low-income countries $(22,23)$. As expected NIV methods such as HHHFNC use are limited in these countries (23). Since our results indicate early and significant improvement in hypoxemia due to pneumonia, we can conclude that good outcomes are associated with HHFNC use. If HHFNC were used in low-income countries, death and disability could be prevented (24).

In recent years, HHHFNC has been preferred commonly for children with bronchiolitis/pneumonia/asthma in many pediatric departments around the world $(9,25)$. However, there are still limited studies which have been conducted in the ED setting on the use of HHHFNC as a respiratory support method for children with pneumonia $(8,9)$. Although the majority of patients included in these studies were infants with acute bronchiolitis, it has been reported that $\mathrm{HHHFNC}$ is also effective in children with pneumonia (1012). In a unique, randomized controlled study, only including children with severe pneumonia, conducted in the ICU, comparing HHHFNC with nasal continuous positive airway pressure (nCPAP), Chisti et al. (24), have determined that there was no difference in treatment failure and intubation rate between an nCPAP group and HHHFNC group. In another study, Er et al. (26) evaluated 64 children aged 0-18 years with bacterial pneumonia receiving $\mathrm{HHHFNC}$ in an ED and found that the therapy success rate was $80 \%$. Our findings are similar to the results of these studies.

It is very important to predict the determining factors of HHHFNC therapy failure in children with RD $(13,14)$. That will enable us to identify patients who will not respond, and thus other treatment options will not be delayed. In our study group, non-responders had a higher respiratory rate at the beginning than responders which is consistent with previous studies $(12,27)$. This may be a reason why HHFNC should not be selected in children with more severe RD.

Early response to HHHFNC is essential when treating a patient with RD and it also can be used as predictor for the main outcomes. A decline in HR and RR have been commonly considered as early signs of a good response to HHHFNC $(10,28)$. Davison et al. (29) found that the surrogate markers (HR and RR) of RD decreased significantly after the first hour of HHHFNC treatment. Similarly, we found that there was a manifest improvement in RR and HR from the initial values to the second hour of therapy.
Since it has been reported that HFNC reduced the rate of intubation and ICU admission in children with RD, it has become increasingly popular in all pediatric settings (25). Our findings showed that the intubation rate for the present cohort was $16 \%$. In a large study conducted with children with RD in an ED, Wing et al. (11), showed that there was an $83 \%$ reduction in the likelihood of intubation in patients receiving HFNC compared with patients who did not get HHFNC. A prospective pilot study has shown that PICU admission is four times less likely in children receiving HHFNC than the standard treatment group (30). In the study by Chisti et al. (24), a total of 79 patients with severe pneumonia were treated with HHHFNC and it was found that among these patients the rate of intubation was $13 \%$.

\section{Study Limitations}

We have some limitations in this study. First, the findings of this study may not be generalizable to other settings because it was a single center study and had an insufficient number of cases. Second, since the study was performed in an ED, we thought 24-hour follow-up was enough. However, because of this decision, we may have lost some data. Third, due to time limitations, we could not evaluate possible confounding variables such as antibiotics, supportive care and so on. Lastly, the study was not a comparative study, hence the efficacy of HFNC therapy versus other treatment options could not be interpreted.

\section{Conclusion}

This study showed that HHHFNC therapy was clinically effective and well tolerated and led to an early impact on patients with SBP in an ED. Treatment failure was higher in patients with a higher respiratory rate. Multicenter, randomized controlled large studies are needed to confirm efficacy of this therapy more accurately for children with pneumonia.

\section{Ethics}

Ethics Committee Approval: This study was approved by Ethics Board of Ege University (approval number: 17-4/6).

Informed Consent: All of the parents of the patients gave their informed consent prior to their child's inclusion in the study.

Peer-review: Externally peer-reviewed.

\section{Authorship Contributions}

Medical Practices: A.Y., E.U.S., Concept: A.Y., E.U.S., Design: A.Y., E.U.S., Data Collection or Processing: A.Y., E.U.S., Analysis or Interpretation: A.Y., E.U.S., Literature Search: A.Y., E.U.S., Writing: A.Y., E.U.S. 
Conflict of Interest: None of the authors had conflict of interest.

Financial Disclosure: The authors declared that this study received no financial support.

\section{References}

1. Neuman MI, Shah SS, Shapiro DI, Hersh AL. Emergency department management of childhood pneumonia in the United States prior to publication of national guidelines. Acad Emerg Med 2013;20:240-6.

2. Kronman MP, Hersh AL, Feng R, Huang YS, Lee GE, Shah SS. Ambulatory visit rates and antibiotic prescribing for children with pneumonia, 1994-2007. Pediatrics 2011;127:411-8.

3. WHO. Estimates Developed by the UN inter-agency group for child mortality estimation, report 2015. Geneva: World Health Organization, 2015.

4. Wardlaw T, Johansson EW, Hodge M. Pneumonia: The Forgotten Killer of Children. UNICEF's Division of Communication. New York: World Health Organization, 2006.

5. Duke T, Wandi $F$, Jonathan $M$, et al. Improved oxygen systems for childhood pneumonia: a multihospital effectiveness study in Papua New Guinea. Lancet 2008;372:1328-33.

6. Subhi R, Adamson M, Campbell H, Weber M, Smith K, Duke $\mathrm{T}$; Hypoxaemia in Developing Countries Study Group. The prevalence of hypoxaemia among ill children in developing countries. Lancet Infect Dis 2009;9:219-27.

7. Vanoni NM, Carugati M, Borsa N, et al. Management of acute respiratory failure due to community-acquired pneumonia: a systematic review. Med Sci (Basel) 2019;7. pii: E10.

8. Mikalsen IB, Davis P, Øymar K. High flow nasal cannula in children: a literature review. Scand I Trauma Resusc Emerg Med 2016;24:93.

9. Wang J, Lee KP, Chong SL, Loi M, Lee JH. High flow nasal cannula in the emergency department: indications, safety and effectiveness. Expert Rev Med Devices 2018;15:929-35.

10. Long E, Babl FE, Duke T. Is there a role for humidified heated high-flow nasal cannula therapy in paediatric emergency departments? Emerg Med I 2016;33:386-9.

11. Wing R, James C, Maranda LS, Armsby CC. Use of highflow nasal cannula support in the emergency department reduces the need for intubation in pediatric acute respiratory insufficiency. Pediatr Emerg Care 2012;28:1117-23.

12. Kelly GS, Simon HK, Sturm J). High-flow nasal cannula use in children with respiratory distress in the emergency department: predicting the need for subsequent intubation. Pediatr Emerg Care 2013;29:888-92.

13. Hansen G, Hochman J, Garner M, Dmytrowich J, Holt T. Pediatric early warning score and deteriorating ward patients on highflow therapy. Pediatr Int 2019;61:278-83.

14. Kamit Can F, Anil AB, Anil M, Zengin N, Durak F, Alparslan C, Goc Z. Predictive factors for the outcome of high flow nasal cannula therapy in a pediatric intensive care unit: Is the $\mathrm{SpO} 2 /$ FiO2 ratio useful? J Crit Care 2018;44:436-44.

15. Bradley JS, Byington CL, Shah SS, et al; Pediatric Infectious Diseases Society and the Infectious Diseases Society of America. The management of community-acquired pneumonia in infants and children older than 3 months of age: clinical practice guidelines by the Pediatric Infectious Diseases Society and the Infectious Diseases Society of America. Clin Infect Dis 2011;53:e25-76.

16. Schuetz P, Wirz $Y$, Sager $R$, et al. Procalcitonin to initiate or discontinue antibiotics in acute respiratory tract infections. Cochrane Database Syst Rev 2017;10:CD007498.

17. Korppi $M$, Kroger L. C-reactive protein in viral and bacterial respiratory infection in children. Scand I Infect Dis 1993;25:20713.

18. Korppi M, Kröger L, Laitinen M. White blood cell and differential counts in acute respiratory viral and bacterial infections in children. Scand J Infect Dis 1993;25:435-540.

19. Shein SL, Slain KN, Rotta AT. High flow nasal cannula flow rates: New data worth the weight. J Pediatr 2017;189:9-10.

20. Duke T, Frank D, Mgone J. Hypoxaemia in children with severe pneumonia in Papua New Guinea. Int J TB Lung Dis 2000;5:511-9.

21. Lazzerini M, Sonego M, Pellegrin MC. Hypoxaemia as a mortality risk factor in acute lower respiratory infections in children in low and middle-income countries: Systematic review and metaanalysis. PLoS One 2015;10:e0136166.

22. Agweyu A, Lilford RJ, English M; Clinical Information Network Author Group. Appropriateness of clinical severity classification of new WHO childhood pneumonia guidance: a multi-hospital, retrospective, cohort study. Lancet Glob Health 2018;6:e74-e83.

23. Von Saint André-Von Arnim AO, Okeyo B, Cook N, Steere $M$, Roberts J, Howard CRA, et al. Feasibility of high-flow nasal cannula implementation for children with acute lower respiratory tract disease in rural Kenya. Paediatr Int Child Health 2018;19:1-7.

24. Chisti MJ, Salam MA, Smith JH, et al. Bubble continuous positive airway pressure for children with severe pneumonia and hypoxaemia in Bangladesh: an open, randomised controlled trial. Lancet 2015;386:1057-65.

25. Kalburgi S, Halley T, Kolaitis IN, Hood K, Mittal V. A Review of Heated High-Flow Nasal Cannula in Pediatrics From Critical Care to Ward Use. Curr Treat Options Peds 2018;4:319-29.

26. Er A, Çağlar A, Akgül F, et al. Early predictors of unresponsiveness to high-flow nasal cannula therapy in a pediatric emergency department. Pediatr Pulmonol 2018;53:809-15.

27. Abboud PA, Roth PJ, Skiles CL, Stolfi A, Rowin ME. Predictors of failure in infants with viral bronchiolitis treated with high-flow, highhumidity nasal cannula therapy. Pediatr Crit Care Med 2012;13:343-9.

28. Kepreotes E, Whitehead B, Attia J, et al. High-flow warm humidified oxygen versus standard low-flow nasal cannula oxygen for moderate bronchiolitis (HFWHO RCT): an open, phase 4, randomised controlled trial. Lancet 2017;389:930-9.

29. Davison M, Watson M, Wockner L, Kinnear F. Paediatric highflow nasal cannula therapy in children with bronchiolitis: A retrospective safety and efficacy study in a non-tertiary environment. Emerg Med Australas 2017;29:198-203.

30. Mayfield S, Bogossian F, O'Malley L, Schibler A. High-flow nasal can- nula oxygen therapy for infants with bronchiolitis: pilot study. I Paediatr Child Health 2014;50:373-8. 